\title{
KELAYAKAN USAHA INDUSTRI IKAN PINDANG SKALA RUMAH TANGGA DI KABUPATEN PATI
}

\section{FEASIBILITY OF HOUSEHOLD SCALE BOILED FISH INDUSTRY IN PATI REGENCY}

\author{
Herna Octivia Damayanti \\ Kantor Penelitian dan Pengembangan Kabupaten Pati \\ Email: octivia_oc@yahoo.co.id
}

\begin{abstract}
Boiled fish is quite popular in Pati Regency. The purpose of this study is to conduct economic analysis of industrial fish boiled in household scale in Pati Regency. The study was conducted in Banyutowo village, Dukuhseti Sub district and Dukutalit village, Juwana Sub district on October 2015. The research method is descriptive quantitative. The primary data were obtained by interviews with boiled fish employers of household scale. While secondary data were derived from relevant documents from marine and fisheries agency of Pati regency. Sampling method was purposive sampling. Respondents were boiled fish employers of household scale. Data were analyzed using analysis of financial feasibility comprising: NPV, R/C ratio, IRR and PP. Results of the research show that: 1) NPV is Rp527,580,791 which means investing for boiled fish industry of household scale in Pati Regency acceptable; 2) The ratio $R / C$ is 1.24 which means feasible to be run and developed; 3) The IRR is 5.11 meaning IRR > relevant interest rate $(4.14 \%)$, so the investment is profitable; 4) PP is 4.8 years or 4 years and 10 months, including the category of medium refund.
\end{abstract}

Keywords: boiled fish, finansial analysis, household scale industry

\begin{abstract}
ABSTRAK
Bentuk olahan hasil perikanan laut yang cukup populer di Kabupaten Pati adalah ikan pindang. Tujuan penelitian adalah untuk melakukan analisis ekonomi terhadap industri ikan pindang dengan skala rumah tangga di Kabupaten Pati. Metode penelitian adalah deskriptif kuantitatif dan dilaksanakan bulan Oktober 2015. Sumber data berupa data primer yang diperoleh dari wawancara dengan pengusaha ikan pindang skala rumah tangga. Sedangkan data sekunder berasal dari dokumen relevan Dislautkan Kab. Pati. Pengambilan sampel dengan purposive sampling. Responden merupakan pengusaha ikan pindang skala rumah tangga. Lokasi penelitian berada di Desa Banyutowo Kecamatan Dukuhseti dan Desa Dukutalit Kecamatan Juwana. Analisis data dengan analisis finansial kelayakan usaha yang terdiri dari: NPV, Rasio R / C, IRR dan PP. Hasil Penelitian yaitu NPV adalah Rp527.580.791 berarti investasi untuk industri ikan pindang skala rumah tangga di Kabupaten Pati dapat diterima. Rasio $R$ / C yaitu 1,24 artinya layak untuk dijalankan dan dikembangkan. IRR yang dihasilkan adalah 5,11 artinya IRR > tingkat bunga relevan yaitu 5,11\% > 4,14\% sehingga investasi dikatakan menguntungkan. PP yang dihasilkan adalah 4,8 tahun atau 4 tahun 10 bulan termasuk kategori pengembalian sedang.
\end{abstract}

Kata kunci: analisis finansial, ikan pindang, industri skala rumah tangga 


\section{PENDAHULUAN}

Salah satu visi yang diusung Kementerian Kelautan dan Perikanan adalah meningkatkan nilai tambah dan daya saing produk kelautan dan perikanan. Selain itu, pengembangan diversifikasi dan pangsa pasar produk hasil kelautan dan perikanan juga dimuat dalam salah satu butir tujuan pembangunan kelautan dan perikanan. Sesuai dengan prinsip blue economy yang salah satunya untuk menciptakan produk turunan, maka produk kelautan dan perikanan yang dihasilkan dapat diolah terlebih dahulu sebelum dipasarkan. Dengan demikian, akan dapat diperoleh nilai manfaat (sumber pendapatan) yang lebih besar dari produk kelautan dan perikanan melalui peningkatan nilai tambah produk (KKP, 2012).

Dahuri dalam Tajerin (2008) bahkan menyebutkan bahwa perikanan dan industri hasil perikanan merupakan sektor yang memiliki keunggulan kompetitif yang berbasiskan sumberdaya alam dan berakar pada perekonomian domestik, jika dikelola secara tepat dan dengan visi kebijakan yang berpihak pada pembangunan perikanan, memungkinkan terciptanya keterkaitan ekonomi yang kuat antara sektor perikanan dengan industri pengolahan hasil perikanan bahkan dengan sektor-sektor lain sehingga pada gilirannya mampu memberikan kontribusi maksimal bagi kemakmuran bangsa.

Hasil perikanan yang lebih banyak dikenal masyarakat adalah ikan. Pendistribusian ikan yang tidak merata merupakan salah satu masalah yang masih dihadapi pada umumnya, di Indonesia. Jarak yang jauh antara pusat produsen dengan pusat konsumen menjadikan pengolahan dan pengawetan ikan mempunyai prospek untuk dikembangkan (Mareta dan Awami, 2011). Pengolahan perlu dilakukan karena mempertimbangkan daya tahan ikan segar, selain itu juga dengan melakukan pengolahan terlebih dahulu diharapkan dapat menambah nilai jual produk perikanan.

Salah satu jenis industri pengolahan ikan adalah dengan cara pemindangan. Industri pemindangan ikan merupakan salah satu upaya untuk mempertahankan atau menjaga kualitas dan harga jual ikan (Larasati, 2007). Pemindangan merupakan cara pengolahan ikan yang masih dilakukan secara sederhana (Tjiptaningdyah, 2012).

Industri pengolahan ikan khususnya pemindangan ikan di Kabupaten Pati terdiri dari dua bentuk yaitu bandeng presto dan ikan pindang. Jika dilihat dari jangka waktu beroperasinya, industri pemindangan ikan di Kabupaten Pati dibedakan menjadi industri pemindangan ikan yang beroperasi sepanjang tahun dan industri pemindangan ikan musiman. Untuk industri pemindangan ikan berbentuk ikan pindang, terdapat dalam berbagai skala industri yaitu skala rumah tangga, kecil, sedang maupun besar.

Masih terdapat industri ikan pindang dengan skala rumah tangga yang menunjukkan bahwa industri ikan pindang tidak hanya dapat dijalankan dengan modal besar saja. Dengan demikian sangat penting untuk dilakukan pengkajian terhadap industri ikan pindang di Kabupaten Pati apakah usaha yang dijalankan secara ekonomi mendatangkan keuntungan terutama bagi industri ikan pindang yang masih berskala rumah tangga. Berdasarkan latar belakang tersebut, maka tujuan penelitian ini adalah 
untuk melakukan analisis ekonomi terhadap industri ikan pindang dengan skala rumah tangga di Kabupaten Pati.

\section{TINJAUAN PUSTAKA}

\section{Industri}

Industri adalah kegiatan memproses atau mengolah barang dengan menggunakan sarana dan peralatan, misal mesin (KBBI, 2014). Menurut BPS Prov. Jateng (2013), sektor industri dibedakan menjadi industri besar, industri sedang, industri kecil, dan industri rumah tangga. Klasifikasi skala industri sebagai berikut:

a. Industri besar adalah perusahaan yang mempunyai tenaga kerja 100 orang atau lebih.

b. Industri sedang adalah perusahaan dengan tenaga kerja 20 orang sampai dengan 99 orang.

c. Industri kecil adalah perusahaan dengan tenaga kerja 5 orang sampai dengan 19 orang.

d. Industri rumah tangga adalah perusahaan dengan tenaga kerja 1 orang sampai dengan 4 orang.

\section{Ikan Pindang}

Ikan pindang merupakan salah satu produk olahan ikan tradisional yang sangat populer dan banyak disukai oleh masyarakat Indonesia. Berdasarkan urutan disposisi dalam pengolahan tradisional, produk pindang menduduki posisi ke-2 setelah produk ikan asin. Beberapa Beberapa jenis pindang yang tersedia di pasar adalah pindang presto, pindang 'badeng' atau 'paso' dan pindang 'naya' atau 'cue'. Pindang presto merupakan jenis pindang yang pada umumnya dibuat dari ikan bandeng, berduri lunak, dan paling awet karena dalam pembuatannya menggunakan pemanas bertekanan (autoclave) dan dikemas dalam kantung plastik hampa udara/vakum. Pindang jenis ini biasa dijajakan di pasar swalayan. Produk pindang 'badeng' atau 'paso' pada umumnya dibuat dari ikan tongkol, dan pindang naya biasanya diolah dari ikan layang atau lemuru yang dipasarkan di pasar tradisional (Ariyani dan Yennie, 2008).

Soeyanto dalam Larasati (2007) menyatakan bahwa ada beberapa cara pembuatan ikan pindang yaitu :

a. Pemindangan sistem Bawean

b. Pemindangan sistem Muncar

c. Pemindangan dengan besek

d. Pemindangan dengan sistem gantung Adapun tujuan utama proses pengolahan pemindangan ikan (Media Penyuluh Perikanan Pati, 2013) adalah :

a. Mencegah/memperlambat proses pembusukan terutama pada saat produksi melimpah. Khusus untuk wilayah pesisir yaitu hasil penangkapan pada musim ikan bulan juli dan Agustus.

b. Menambah nilai jual produk mentah menjadi bahan olahan.

c. Mempertahankan kualitas / mutu dan meningkatkan harga jual ikan.

d. Meningkatkan pendapatan bakul ikan.

e. Membuat nilai tambah sehingga dapat meningkatkan penjualan

Memperhatikan unsur kesehatan dan kebersihan ikan.

\section{Industri Ikan Pindang Di Kabupaten Pati}

Jumlah industri pemindangan ikan di Kabupaten Pati adalah 104 industri yang terdiri dari 83 industri ikan pindang dan 21 industri bandeng presto (Dislautkan Kab. Pati, 2014).

Untuk industri ikan pindang, skala industri sedang dan besar berjumlah 30 industri dan industri ikan pindang skala rumah tangga dan kecil berjumlah 53 industri. Industri ikan pindang skala sedang dan besar berada di Kecamatan 
Juwana, sedangkan industri ikan pindang skala rumah tangga dan kecil berada di Kecamatan Juwana, Dukuhseti, Tayu, Margoyoso, Wedarijaksa, Pati dan Jakenan (Dislautkan Kab. Pati, 2014).

\section{METODE PENELITIAN}

Penelitian ini menggunakan metode deskriptif kuantitatif dan dilaksanakan pada bulan Oktober 2015. Sumber data berupa data primer yang diperoleh dari wawancara dengan pengusaha ikan pindang skala rumah tangga. Sedangkan data sekunder berasal dari dokumen relevan Dislautkan Kab. Pati. Metode yang digunakan dalam pengambilan sampel responden adalah purposive sampling. Responden penelitian merupakan pengusaha ikan pindang skala rumah tangga. Lokasi penelitian berada di Desa Banyutowo Kecamatan Dukuhseti dan Desa Dukutalit Kecamatan Juwana. Analisis data dengan analisis finansial kelayakan usaha yang terdiri dari:

\section{a) NPV (Net Present Value)}

NPV atau nilai sekarang bersih adalah jumlah nilai sekarang dari manfaat bersih. Secara matematis, NPV dapat dituliskan (Abelson dalam Saputra dkk, 2011) :

$\mathrm{NPV}=\sum_{\mathrm{t}=1}^{\mathrm{n}} \frac{\mathrm{Bt}-\mathrm{Ct}}{(1+\mathrm{i}) \mathrm{t}}$

Keterangan:

$\mathrm{B}$ = manfaat ke-t

$\mathrm{C}=$ biaya ke-t

$\mathrm{i}=$ suku bunga (discount rate) per tahun

$\mathrm{t}=$ jangka waktu perhitungan

$\mathrm{n}=$ jumlah tahun

Kriteria NPV yaitu: (1) NPV positif, maka investasi diterima; (2) NPV negatif, sebaiknya investasi ditolak.

\section{b) Revenue-Cost Ratio (Rasio R/C)}

Analisis Retenue-Cost (Rasio R/C) adalah perbandingan antara total pendapatan dan total biaya dari suatu usaha. Analisis ini dilakukan untuk menganalisis performa usaha yang dikaji melalui pendapatan usahanya. Secara sistematis dituliskan:

$$
\begin{aligned}
\operatorname{Profit}(\pi) & =\mathrm{TR}-\mathrm{TC} \ldots \ldots \ldots \ldots \ldots \ldots \ldots \\
& =(\mathrm{p} . \mathrm{C})-(\mathrm{FC}+\mathrm{VC}) \\
\text { Rasio R/C } & =\mathrm{TR} / \mathrm{TC} \ldots \ldots \ldots \ldots \ldots \ldots \ldots \ldots \ldots \ldots \ldots
\end{aligned}
$$

Keterangan:

$\pi \quad=$ profit $(\mathrm{Rp})$

$\mathrm{TR}=$ Total Revenue/pendapatan total (Rp)

$\mathrm{TC}=$ Total Cost / biaya total (Rp)

$\mathrm{FC}=$ Fixed Cost / biaya tetap total (Rp)

$\mathrm{VC}=$ Variable Cost / biaya variabel total (Rp)

$\mathrm{p}=\operatorname{harga~ikan}(\mathrm{Rp} / \mathrm{kg})$

$\mathrm{C}=$ total tangkapan $(\mathrm{kg})$

Adapun kriteria hasil perhitungan ratio $\mathrm{R} / \mathrm{C}$ adalah: (1) Jika $\mathrm{R} / \mathrm{C}$ ratio $>1$, maka usaha yang dijalankan mengalami keuntungan atau layak untuk dikembangkan; (2) Jika $\mathrm{R} / \mathrm{C}$ ratio $<1$, maka usaha tersebut mengalami kerugian atau tidak layak untuk dikembangkan; (3) Jika $\mathrm{R} / \mathrm{C}$ ratio $=1$, maka usaha berada pada titik impas (Break Event Point).

\section{c) IRR (Internal Rate Of Return)}

Internal Rate of Return (IRR) merupakan alat untuk mengukur tingkat pengembalian hasil intern (Kasmir dan Jakfar, 2009). Secara matematis dirumuskan sebagai berikut :

$\mathrm{IRR}=\mathrm{i}_{1}+\frac{\mathrm{NPV}_{1}}{\mathrm{NPV}_{1}-\mathrm{NPV}_{2}}\left(\mathrm{i}_{2}-\mathrm{i}_{1}\right)$ 
Keterangan:

i1 = tingkat bunga 1 (tingkat discount rate yang menghasilkan NPV 1)

i2 = tingkat bunga 2 (tingkat discount rate yang menghasilkan NPV 2)

NPV1 = Net Present Value 1

NPV 2= Net Present Value 2

Kriteria IRR yaitu: (1) IRR > tingkat bunga relevan, maka investasi dikatakan menguntungkan; (2) IRR < tingkat bunga relevan, maka investasi dikatakan merugikan.

\section{d) PP (Payback Periods)}

Payback Period merupakan periode yang diperlukan untuk menutup kembali pengeluaran investasi. Secara sederhana dapat dituliskan (Riyadi dan Wijayanto, 2012):

$P P=\frac{\text { Nilai Investasi }}{\text { Kas masuk bersih }} \times 1$ tahun

Kriteria: (1) Nilai Payback Period kurang dari 3 tahun kategori pengembalian cepat; (2) Nilai Payback Period 3 - 5 tahun kategori pengembalian sedang; (3) Nilai Payback Period lebih dari 5 tahun kategori lambat.

\section{HASIL DAN PEMBAHASAN}

\section{Industri Ikan Pindang Skala Rumah Tangga}

Biaya investasi yang dikeluarkan pengusaha ikan pindang skala rumah tangga terdiri dari biaya penyusutan pabrik dan biaya penyusutan peralatan. Untuk bangunan pabrik, berdasarkan hasil pengamatan dan wawancara dengan responden pengusaha ikan pindang skala rumah tangga hanya bangunan semipermanen yang diletakkan di sekitar rumah utama. Bangunan semipermanen ini biasanya berdinding kayu dan beratap asbes. Bangunan pabrik tidak hanya berupa bangunan semipermanen, tetapi ada juga yang menyatu dengan dapur rumah utama. Namun sudah jarang yang menyatukan pabrik dengan dapur karena dinilai kurang efisien, sehingga pengusaha ikan pindang skala rumah tangga memilih untuk membangun bangunan semipermanen di sekitar rumah utama yang khusus digunakan untuk pembuatan ikan pindang. Selain itu, pabrik ini juga digunakan untuk penyimpanan peralatan dan semua bahan yang digunakan untuk memproduksi ikan pindang. Biaya penyusutan peralatan dikeluarkan untuk pembelian dandang besar. Dandang besar ini digunakan untuk proses perebusan ikan. Pengusaha ikan pindang skala rumah tangga menggunakan peralatan produksi berupa dandang besar dengan kapasitas sekali produksi mencapai $10 \mathrm{~kg}$ sehingga cepat lambatnya proses produksi sangat tergantung pada jumlah peralatan (dandang besar) yang dimiliki oleh pengusaha ikan pindang.

Biaya operasional yang dikeluarkan terdiri dari biaya pembelian bahan baku, pembelian besek, pembelian bahan tambahan dan upah tenaga kerja. Untuk biaya pembelian bahan baku sangat tergantung dari jumlah produksi per hari. Produksi industri ikan pindang skala rumah tangga berkisar antara $10 \mathrm{~kg}-20 \mathrm{~kg}$ per hari (Dislautkan Kab. Pati, 2014). Harga bahan baku ikan segar (ikan layang) yang berlaku saat penelitian Rp10.000/kg. Dengan demikian, jumlah biaya pembelian bahan baku sangat tergantung dari jumlah produksi dan harga bahan baku yang berlaku.

Biaya operasional selanjutnya adalah biaya pembelian besek. Besek digunakan sebagai tempat ikan pindang hasil produksi. Besek yang dimaksud terbuat dari anyaman bambu yang dibuat renggang dan berbentuk persegi panjang atau bundar. Besar besek yang digunakan tergantung besar ikan dan jumlah ikan 
yang akan dimuat dalam 1 buah besek. Jumlah ikan yang dimuat dalam 1 besek adalah 2 sampai 5 ekor tergantung dari besar kecil ukuran ikan. Besek-besek ini dijual dengan hitungan per 100 buah dengan harga Rp25.000. Jumlah besek yang dipakai sangat tergantung dari jumlah produksi dan ukuran ikan. Berdasarkan wawancara dengan responden pengusaha ikan pindang skala rumah tangga, rata-rata penggunaan besek untuk pengusaha ikan pindang skala rumah tangga adalah 100 buah besek dalam 1 hari produksi.

Tabel 1.

Gambaran Industri Ikan Pindang Skala Rumah Tangga di Kabupaten Pati

\begin{tabular}{|c|c|c|c|}
\hline \multicolumn{4}{|c|}{ Biaya Investasi/biaya tetap } \\
\hline No & Komponen/uraian kegiatan & Keterangan & Jumlah (Rp) \\
\hline 1 & Biaya penyusutan pabrik & & 3.000 .000 \\
\hline 2 & Biaya penyusutan peralatan & 1 dandang besar & 200.000 \\
\hline \multicolumn{3}{|c|}{ Jumlah } & 3.200 .000 \\
\hline \multicolumn{4}{|c|}{ Biaya Operasional } \\
\hline No & Komponen/uraian kegiatan & Keterangan & Jumlah (Rp) \\
\hline 1 & Biaya pembelian bahan baku & $\begin{array}{l}1 \text { kali produksi }=20 \mathrm{~kg}, \\
\mathrm{Rp} 10.000 / \mathrm{kg}\end{array}$ & 200.000 \\
\hline 2 & Biaya pembelian besek & 100 buah & 25.000 \\
\hline 3 & Biaya transportasi & Rp20.000/hari & 20.000 \\
\hline 4 & Biaya pembelian bahan tambahan & $\begin{array}{l}\text { garam } 5 \mathrm{~kg}(\mathrm{Rp} 1.000 / \mathrm{kg}) \\
\text { plastik Rp3.000/pak, } \\
\text { kayu bakar Rp35.000 }\end{array}$ & 43.000 \\
\hline 5 & Biaya upah tenaga kerja & 2 orang ( $\mathrm{Rp} 25.000 /$ orang) & 50.000 \\
\hline \multicolumn{3}{|c|}{ Jumlah } & 338.000 \\
\hline \multicolumn{3}{|c|}{ Biaya Operasional untuk 300 hari (1 tahun) } & 101.400 .000 \\
\hline \multicolumn{4}{|c|}{ Total Produksi/tahun $=6.000 \mathrm{~kg}$} \\
\hline 1 & Pendapatan 1 tahun & $\begin{array}{l}20 \mathrm{~kg}, 1 \mathrm{~kg}=20 \text { ekor, per } \\
\text { besek isi } 5 \text {, harga Rp5000 }\end{array}$ & 120.000 .000 \\
\hline
\end{tabular}

Sumber: Pengolahan Data (2016)

Biaya transportasi dikeluarkan untuk proses penjualan ikan pindang. Mayoritas pengusaha ikan pindang skala rumah tangga melakukan produksi sekaligus penjualan secara langsung kepada konsumen yaitu ke pasar tradisional yang berada di sekitar tempat tinggalnya. Berdasarkan penuturan responden pengusaha ikan pindang skala rumah tangga, untuk proses pengangkutan produk, pada umumnya menggunakan angkutan tradisional, seperti andong (dokar). Untuk sekali perjalanan mengeluarkan biaya Rp10.000 sehingga dalam sehari membutuhkan biaya Rp20.000 untuk sekali pulang pergi.

Biaya pembelian bahan tambahan berupa biaya pembelian garam. Rata-rata penggunaan garam untuk produksi ikan pindang skala rumah tangga adalah $5 \mathrm{~kg}$ dalam 1 hari produksi. Garam yang digunakan merupakan garam krosok atau garam yang tanpa diolah. Garam ini dibeli langsung dari petani garam. Sedangkan 
untuk biaya pembelian plastik pembungkus sehari produksi menghabiskan 1 pak. Sedangkan untuk proses perebusan menggunakan kayu bakar yang dibeli dari bakul kayu bakar dengan harga 1 paket (terdiri dari beberapa ikat kayu bakar).

Tenaga kerja industri ikan pindang skala rumah tangga rata-rata berjumlah 2 orang. Untuk biaya upah tenaga kerja diberi upah sebesar Rp25.000/hari. Pada kenyataannya, pengusaha sendiri juga ikut melakukan proses produksi sehingga tenaga kerja menjadi 3 orang.

Untuk menghitung pendapatan usaha dilakukan dengan mengurangkan pendapatan dengan jumlah biaya (biaya investasi dan biaya operasional). Pendapatan diperoleh dengan mengalikan jumlah besek ikan pindang yang telah diproduksi dengan harga jual ikan pindang per besek. Sebagai contoh untuk industri ikan pindang skala rumah tangga yaitu jumlah besek yang dihasilkan sebanyak 80 besek dan harga jual yang berlaku saat penelitian adalah Rp 5000. Dengan demikian, pendapatan yang diperoleh selama 1 tahun (jumlah hari produksi 300 hari) mencapai Rp120.000.000.

\section{Analisis Finansial Industri Ikan Pindang Skala Rumah Tangga}

a) NPV (Net Present Value) dan Return-Cost Ratio (Rasio R/C)

NPV selama 5 tahun untuk industri ikan pindang skala rumah tangga di Kabupaten Pati adalah Rp 527.580.791. NPV bernilai positif berarti investasi untuk industri ikan pindang skala rumah tangga di Kabupaten Pati dapat diterima.

Pada tahun pertama, industri ikan pindang skala rumah tangga di Kabupaten Pati telah memperoleh benefit sebesar Rp. 120.000.000. Hal ini menunjukkan bahwa pada tahun pertama keberadaan industri ikan pindang skala rumah tangga di Kebupaten Pati mampu mengembalikan modal investasi dan masih memperoleh keuntungan usaha.

Untuk rasio $\mathrm{R} / \mathrm{C}$ industri ikan pindang skala rumah tangga yaitu 1,24. Artinya, rasio R/C lebih dari 1 sehingga usaha industri ikan pindang skala rumah tangga ini layak untuk dijalankan dan dikembangkan karena setiap pengeluaran Rp1 akan menghasilkan Rp1.240.

Tabel 2.

NPV dan Rasio R/C Industri Ikan Pindang Skala Rumah Tangga di Kabupaten Pati

\begin{tabular}{|c|c|c|c|}
\hline Tahun & Investasi & Benefit & Total Cost \\
\hline 0 & \multirow[t]{6}{*}{3.200 .000} & 0 & 3.200 .000 \\
\hline 1 & & 120.000 .000 & 104.600 .000 \\
\hline 2 & & 124.968 .000 & 104.732 .480 \\
\hline 3 & & 130.141 .675 & 104.870 .445 \\
\hline 4 & & 135.529 .541 & 105.014.121 \\
\hline 5 & & 141.140 .464 & 105.163 .746 \\
\hline \multicolumn{2}{|c|}{ Jumlah } & 651.779 .679 & 527.580 .791 \\
\hline & $\mathrm{R} / \mathrm{C}$ & & 1,24 \\
\hline
\end{tabular}

Sumber: Pengolahan Data (2016) 
b) IRR (Internal Rate Of Return)

Tabel 3.

IRR Industri Ikan Pindang Skala Rumah Tangga

di Kabupaten Pati

\begin{tabular}{crrr}
\hline Tahun & \multicolumn{1}{c}{ benefit } & \multicolumn{1}{c}{ Cost } & Net Benefit \\
\hline 0 & 0 & 3.200 .000 & -3.200 .000 \\
1 & 120.000 .000 & 104.600 .000 & 15.400 .000 \\
2 & 124.968 .000 & 104.732 .480 & 20.235 .520 \\
3 & 130.141 .675 & 104.870 .445 & 25.271 .231 \\
4 & 135.529 .541 & 105.014 .121 & 30.515 .419 \\
5 & 141.140 .464 & 105.163 .746 & 35.976 .718 \\
\hline \multicolumn{5}{c}{ IRR } \\
\hline
\end{tabular}

Sumber: Pengolahan Data (2016)

Nilai IRR yang dihasilkan adalah 5,11. Artinya, IRR > tingkat bunga relevan yaitu $5,11 \%>4,14 \%$ sehingga investasi dikatakan menguntungkan. Berdasarkan wawancara dengan responden pengusaha ikan pindang skala rumah tangga menyatakan bahwa usaha pembuatan ikan pindang walaupun berskala rumah tangga akan terus dilakukan karena keyakinan bahwa produknya akan laku terjual dan tidak akan mengalami kerugian dengan harga jual yang berlaku saat ini yaitu
Rp5.000/besek. Selain itu, membuat pindang merupakan mata pencaharian utama bagi pengusaha ikan pindang skala rumah tangga.

\section{c) PP (Payback Periods)}

Nilai PP yang dihasilkan adalah 4,8 tahun. Artinya, nilai Payback Period industri ikan pindang skala rumah tangga di Kabupaten Pati termasuk kategori pengembalian sedang yaitu 4,8 tahun atau 4 tahun 10 bulan.

Tabel 4.

PP Industri Ikan Pindang Skala Rumah Tangga di Kabupaten Pati

\begin{tabular}{crr}
\hline Tahun & PV Benefit & \multicolumn{1}{l}{ Saldo } \\
\hline 1 & -3.200 .000 & $\mathbf{- 3 . 2 0 0 . 0 0 0}$ \\
2 & $\mathbf{1 5 . 4 0 0 . 0 0 0}$ & 12.200 .000 \\
3 & 20.235 .520 & 32.435 .520 \\
4 & 25.271 .231 & 57.706 .751 \\
5 & 30.515 .419 & 88.222 .170 \\
\hline \multicolumn{3}{c}{} \\
\hline
\end{tabular}

Sumber: Pengolahan Data (2016) 


\section{KESIMPULAN DAN SARAN}

\section{Kesimpulan}

Analisis finansial terhadap industri ikan pindang skala rumah tangga di Kabupaten Pati yaitu: NPV adalah Rp527.580.791 berarti investasi untuk industri ikan pindang skala rumah tangga di Kabupaten Pati dapat diterima. Rasio R/C yaitu 1,24 artinya layak untuk dijalankan dan dikembangkan. IRR yang dihasilkan adalah 5,11 artinya IRR > tingkat bunga relevan yaitu $5,11 \%>$ $4,14 \%$ sehingga investasi dikatakan menguntungkan. PP yang dihasilkan adalah 4,8 tahun atau 4 tahun 10 bulan termasuk kategori pengembalian sedang.

\section{Saran}

1) Pemerintah Daerah Kabupaten Pati melalui Dinas Kelautan dan Perikanan Kabupaten Pati supaya lebih banyak memberikan perhatian dan dukungan berupa bantuan modal usaha terutama pada industri yang masih berskala kecil dan rumah tangga agar dapat berkembang dan meningkatkan usahanya menjadi lebih besar.

2) Pemerintah Daerah Kabupaten Pati melalui Dinas Perindustrian dan Perdagangan Kabupaten Pati supaya lebih banyak memberikan perhatian dan dukungan berupa pelatihan usaha dan perluasan jaringan pemasaran khususnya untuk industri ikan pindang skala rumah tangga dan kecil.

\section{DAFTAR PUSTAKA}

Ariyani, F. dan Y. Yennie. 2008. Pengawetan Pindang Ikan Layang (Decapterus russelli) Menggunakan Kitosan. Jurnal Pascapanen dan Bioteknologi
Kelautan dan Perikanan. Vol 3 (2) : 139-146.

Badan Pusat Statistik Provinsi Jawa Tengah. 2013. Jawa Tengah Dalam Angka 2012. Semarang: BPS Provinsi Jawa Tengah.

Dinas Kelautan dan Perikanan Kabupaten Pati. 2014. Profil Pindang Pati. Pati: Dislautkan Kabupaten Pati.

Kamus Besar Bahasa Indonesia. 2014. Kamus Besar Bahasa Indonesia (KBBI) online_industri. http://kbbi.web.id, diakses tanggal 20 Januari 2014.

Kasmir dan Jakfar, 2009. Studi Kelayakan Bisnis.Kencana Prenada Media Group. Jakarta.

Kementerian Kelautan dan Perikanan. 2012. Visi, Misi, Tujuan dan Sasaran Strategis. www.kkp.go.id/index.php/arsiplc/8 278/visi-misi-tujuan-dan-sasaranstrategis/?category-id=65, diakses tanggal 21 Januari 2014.

Larasati, E. 2007. Analisis Usaha Pemindangan Ikan Di Kabupaten Pati. Skripsi. Fakultas Pertanian. Surakarta: Universitas Sebelas Maret.

Media Penyuluh Perikanan Pati. 2013. Pengolahan Hasil Perikanan Dengan Pemindangan. http://media penyuluh perikanan pati.blogspot.com/2013/06/pengola han-hasil-perikanan-dengan.html. Diakses tanggal 20 Januari 2014.

Mareta, D. T., S. N. Awami. 2011. Pengawetan Ikan Bawal Dengan Pengasapan Pemanggangan. Mediagro 7(2): 33-47.

Riyadi, P. H., D. Wijayanto. 2012. Buku Ajar Manajemen Industri Perikanan. Semarang: LPPMP UNDIP. 
Saputra, S. W., A. Solichin, D. Wijayanto dan F. Kurohman, 2011. Produktivitas Dan Kelayakan Usaha Tuna Longliner Di Kabupaten Cilacap Jawa Tengah. Jurnal Saintek Perikanan, Vol 6 (2): 84-91.

Tajerin. 2008. Sumber-Sumber Pertumbuhan Output Perikanan Dalam Perekonomian Indonesia Periode 1990-2000: Pendekatan Analisis Menggunakan Input-Output Dekomposisi Faktor. Jurnal Kebijakan dan Riset Sosial Ekonomi Kelautan Perikanan 3(1): 35-54.
Tjiptaningdyah, R. 2012. Pengaruh Pemindangan Dan Pengasapan Terhadap Masa Simpan Ikan Lemuru (Sardinella longiceps). Neptunus 18(1): 80-86.

\section{BIODATA PENULIS}

Herna Octivia Damayanti, lahir 6 Oktober 1985 di kota Kudus Jawa Tengah. Pendidikan S1 Program Studi Oseanografi Jurusan Ilmu Kelautan Fakultas Perikanan dan Ilmu Kelautan Universitas Diponegoro tahun 2009. Saat ini bekerja sebagai Peneliti di Kantor Penelitian dan Pengembangan Kabupaten Pati. 